\title{
Application of Equity Structure Innovation Based on Information Management Technology in Multiple-Holding Start-ups
}

\author{
Liu Xianming ${ }^{1,}$, Zhong Zhengqing ${ }^{2}$, Liu Songyue ${ }^{3}$ \\ ${ }^{1}$ Hubei Polytechnic University Jilin, China \\ ${ }^{2}$ Hubei Polytechnic University Hubei, China \\ ${ }^{3}$ Wuhan University of Technology Jilin, China
}

\begin{abstract}
In modern management, the design of equity structure exerts an important influence on the operation and development of a company. A scientific and reasonable equity structure for companies in the early days will prevent and control their own risks in different stages, while the application of information management technology is also indispensable in the current big data environment. Therefore, this paper determined the weight by means of the 0-9 scoring method to evaluate the importance of equity and propose the idea of innovative design for the equity structure in multiple-holding start-ups. Eventually, a tool to optimize equity structure was designed to serve as information management technology for risk prevention and control in start-ups. It can effectively safeguard the rights and interests of all the shareholders based on various ranks, demonstrating the sincerity of the founding team to the greatest extent. By setting a rational proportion and making fine-tuning in accordance with the needs of all stakeholders, both the decision rights of the founding team and the trust of the external investors are guaranteed.
\end{abstract}

\section{Main types of the Equity Structure}

\subsection{Classifying according to the different formation}

\subsubsection{Unitary Share Structure}

Unitary share structure, referring to the integration of equity proportion, voting right and bonus right, is very simple, but the downside is that the business may get stuck. (Wei Min, 2017)

\subsubsection{Dual-Class Share Structure}

Dual-class share structure refers that the proportion of shares, voting rights and dividend right are not equal, which needs to be designed separately according to the shareholders' rights. This structure exists the same share with different rights-- high-voting stock means more decision-making power, which is an effective method to control the company by separating control from cash flow rights by cross-ownership. However, its defect lies in that it violates the shareholder governance structure of modern companies, which is not conducive to the protection of shareholders' interests and may lead to the dictatorship in management.

\subsection{3 $4 * 4$ Share Structure}

Based on the dual-class share structure, $4 * 4$ share structure divides the shareholders of the company into four types, namely investors, partners, the founder and employees. Overall arrangements of relevant personnel can be made according to their rights to achieve the goals in advance. It is suitable for entrepreneurial or innovative enterprises. (Wei Min, 2017)

\subsection{Classifying according to the different degree of equity concentration}

\subsubsection{High concentration of equity}

High concentration of equity means that the absolute holding stockholder generally owns more than or equal to $2 / 3$ company's shares, having absolute control. The structure is stable, but the conflicts between dominant and minority shareholders may happen easily, which are difficult to check and balance.

\subsubsection{Highly dispersion of equity}

Highly dispersion of equity means that there is no big shareholder in a company. The right of ownership is separated from the right of management, and the proportion of shares held by individual shareholder is less than $1 / 10$. There is no absolute holding shareholder, and 
the proportion of shareholders is generally low, which is difficult to check and balance.

\subsubsection{Over-average of equity}

Due to the poor knowledge of the importance of equity structure design, the partners of start-ups in the early stage evenly distribute the shares, for example, each of the four partners accounts for $1 / 4$. The structure would easily result in a sense of unfairness due to the uneven individual ability and pay, more importantly, it is not conducive to make major decisions for a company.

\subsubsection{Relative concentration of equity}

Relative concentration of equity means that there are bigger controlling shareholders in a company. There are two circumstances: indirect holding: $1 / 3<$ the proportion of shares held by shareholders $\leqq 1 / 2$, with a major matter veto power; relative holding: $1 / 2 \leqq$ the proportion of shares $<2 / 3$. It is an ideal structure with a strong efficiency to check and balance.

\section{Equity and interests from all parties of the start-ups}

\subsection{Partners}

The respective control rights of the founding partner and the founding team need to be guaranteed, and the only final decision maker is required to improve the efficiency of decision-making. Moreover, the founding team should be united to make consistent decisions inside and control the development of the company.

\subsection{Investors}

The trust mechanism in partners should be established to protect the external investors' interests in that they tend to invest more money but hold fewer shares.

\subsection{Employees}

The employees are indispensable to the development of a start-up. Therefore, equity incentive is a relatively effective guarantee mechanism. Employees associate themselves with the development of the team and benefits are needed to ensure that their initial investment is not wasted and that their personal development in the company will not be weakened in the future.

\section{Multiple-holding ownership structure innovation design}

\subsection{Innovative ownership structure}

\subsubsection{Partnership}

\section{Equity Structure}

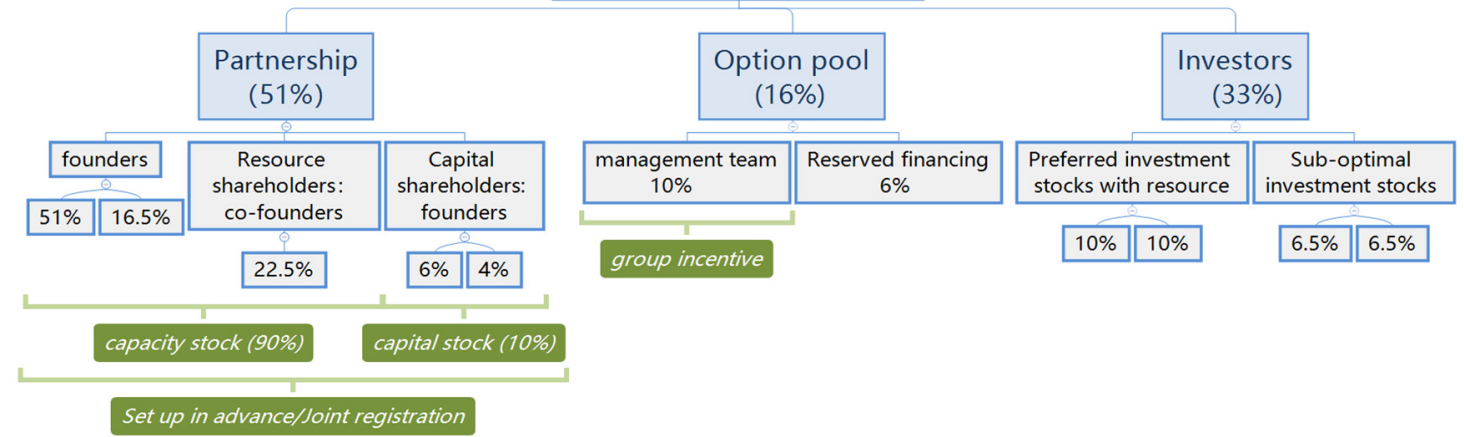

Fig 1. Innovative ownership structure of the LLC

The partnership, accounting for 51\% of the LLC's shares, owns relative control rights. The subdivided three parts are the founder, shareholders invested with resources and shareholders invested with capital. First of all, in the partnership, the founder holds $62.31 \%$ of the shares without contributed capital but with RMB 2 per share as he/she is fully engaged in running the company. For shareholders with resources, they can choose whether to invest in the company or not as they are willing to provide their resources and actively use their own influence to run the company. They own $27.69 \%$ of the shares without contributed capital but with RMB 2 per share. Thirdly, shareholders invested with capital are partners who invest and actively participate in the operation of the company, whose shares account for $10 \%$ of the partnership with RMB 2 per share. The total capital invested by them amounts to RMB 1,000,000.

\subsubsection{Founder}

The founder, constrained by the liability, possesses $6 \%$ of the LLC's equity. It will take three years for the founder to invest money and another three to transform the shares into his/her own with RMB 4 per share. Shares shall be allocated according to the performance indicators of the founder. And the distribution rules are as follows: $0 \leq$ work completion $\leq 50 \%$, no share; $50 \%<$ work completion $<100 \%$, share of $1 \%$; work completion $\geq 100 \%$, share of $2 \%$. After reaching the standard of $6 \%$ of shares, the corresponding target, namely the process of transforming shares, will continue to be completed annually. Once the transformed shares are up to $6 \%$, they 
can be converted into individual shares. The total capital invested by founder reaches RMB 240,000.

3) Employee Stock Ownership Plan (ESOP)

Held by the founder, the ESOP accounts for $10 \%$ of the LLC's equity, which acts as the annual performance reward for the management team and the retention system of outstanding professional managers. It will take five years to reach the standard and another five to transform the shares into their own with RMB 4 per share. Shares shall be allocated according to the performance indicators of the sponsors. And the distribution rules are as follows: $0 \leq$ work completion $\leq 50 \%$, no share; $50 \%<$ work completion $<100 \%$, share of $1 \%$; work completion $\geq 100 \%$, share of $2 \%$. After reaching the standard of $10 \%$ of shares, the corresponding target, namely the process of transforming shares, will continue to be completed annually. Transformed shares up to $10 \%$ can be converted into individual shares. As a group incentive, no investment is required.

4) Investors

External investors account for $33 \%$ of the shares. They are divided into two types which consist of the preferred investors with resources and the sub-optimal investors

\begin{tabular}{|l|l|l|l|l|l|l|l|l|l|l|}
\hline & A & B & C & score & revision & final score & ratio & $\begin{array}{l}\text { capacity stock } \\
(90 \%)\end{array}$ & $\begin{array}{l}\text { capital stock } \\
(10 \%)\end{array}$ & shares of partners \\
\hline A & - & 9 & 9 & 18 & 0 & 18 & $69.23 \%$ & $62.31 \%$ & $5 \%$ & $67.31 \%$ \\
\hline B & 3 & - & 3 & 6 & 0 & 6 & $23.08 \%$ & $20.77 \%$ & 0 & $20.77 \%$ \\
\hline C & 1 & 1 & - & 0 & 0 & 2 & $7.69 \%$ & $6.92 \%$ & $5 \%$ & $11.92 \%$ \\
\hline
\end{tabular}

Fig 2. shares of partners

According to the 0-9 score method, the founder A is fully engaged in the company's operation. Compared with the co-founders $\mathrm{B}$ and $\mathrm{C}$, both of whose importance indicators are 9, A's total score is 18. The importance indicator of $\mathrm{B}$ relative to $\mathrm{A}$ and $\mathrm{C}$ is 3 respectively, with a total point of 6; with the importance indicator relative to $\mathrm{A}$ and $\mathrm{B}$ being 1 respectively, $\mathrm{C}$ scores a total point of 2 . When the correction value is 0 , the proportions of $\mathrm{A}, \mathrm{B}$ and $\mathrm{C}$ are $69.23 \%, 23.08 \%$ and $7.69 \%$, respectively. As for the shares in the partnership, they are composed of capacity shares $(90 \%)$ and capital shares (10\%) among which only $\mathrm{A}$ and $\mathrm{C}$ purchase capital shares, accounting for $5 \%$ each. Based on this, the proportion of shares held by the final three parties is obtained--the founder A accounts for $67.31 \%$ of the shares of the partnership, while the co-founders B and $\mathrm{C}$ account for $20.77 \%$ and $11.92 \%$ respectively. (see Table 3-2)

The founder, whose shares account for $67.31 \%$ of the total, own absolute control rights, which can preserve his/her core interests.

Investors hold $33 \%$ of the shares which are divided into two kinds: one is the preferred investors with resource; the other is the sub-optimal investors with mere capital input.

Preferred investors with resource can be divided into two kinds. One is willing to invest money and resources and actively participate in the operation. These stocks account for $8 \%$ of the shares and are subscribed by RMB 20 per share, with a total investment of RMB 1.6 million, applying to establishment registration. The other is willing to invest money and resources as well, but voluntarily with mere capital input.

\subsection{Analysis of design logic}

The basic principle of equity structure design proposed in this paper is to meet the needs of all staff. The partners of partnership holds $51 \%$ of the total shares and has relative control for the purpose of external consistency. The founder accounts for $6 \%$ of the shares with a total investment of nearly RMB one million. In addition, he/she will devote himself/herself operating the enterprise, which is enough to prove his/her attitude and enhance the confidence of the external investors. The investment of ESOP accounts for $10 \%$ of the total equity investment, which is held by the founder and acts as the annual performance reward for the team and the retention system of outstanding professional managers. The above three parts constitute $67 \%$ of the LLC's shares, so the partners have absolute control.

In the partnership, shares are held by three parties: the founder, shareholders invested with resources and shareholders invested with capital.

participating in the operation. This kind of shares accounts for $8 \%$ of the equity and is subscribed by RMB 40 per share, with a total investment of RMB 3.2 million, applying to rent factory buildings.

Sub-optimal investors with mere capital input can be divided into two kinds. One takes long-term investments, which accounts for $8 \%$ of the shares and is subscribed by RMB 100 per share, with a total investment of RMB 8 million, applying to the procurement of equipment. The other takes short-term investments, which accounts for $9 \%$ of the shares and is subscribed by RMB 150 per share, with a total investment of RMB 13.5 million, applying to the capital turnover.

\subsection{Analysis of distribution mechanism}

The partnership enterprise is exempt from VAT and income tax, and pays individual income tax directly as individual business. Therefore, its distribution mechanism is based on project agreement instead of share distribution. Priority bonus level: preferred investment stocks with resource $>$ management team $>$ initiators $>$ stakeholders $>$ partnership. The purpose is to ensure the start-up costs, declare the attitude of the partners and enhance the confidence of external investors.

First, protecting the interests of preferred investors with resource. All of the annual distributable profits that are less than or equal to $10 \%$ of the total investment of investors go to the preferred investment shareholders; $70 \%$ of the annual distributable profits that are between $10 \% \sim 20 \%$ shall be given to them; $50 \%$ of the annual 
distributable profits that are between $20 \% \sim 30 \%$ shall be allocated to them; and of the annual distributable profits that are greater than $30 \%, 30 \%$ go to them as well. Second, protecting the interests of the management team. After the investment shareholders allocate the profits, the operating team shall withdraw $10 \%$ of the distributable profits. Third, protecting the interests of the founder. The founder will take $6 \%$ after the management team (allocating in proportion to the number of shares owned. curing shares refer to 3-year standard plus 3-year conversion). Fourth, protecting the interests of stakeholders. The remaining distributable profits belonging to the partnership shall be determined by the founder to coordinate stakeholder costs. And the limited partners should be informed of the amount or proportion determined in the annual plan centering on the development priorities. Finally, distributing the rest within the partnership.

\section{Application of innovative equity structure in corporate risk prevention and control}

\subsection{Market risk}

Due to the market risk in the early days of registration, the company pays more attention to the market development. And at this time, customer resources are particularly important, and the main risk comes from whether the profit and loss are balanced. Therefore, in the early stage of entrepreneurship, investment stocks with resources should be given priority, so as to develop the market and gradually run the company normally.

\subsection{Funding risk}

With the development of the market, both the sales volume and the number of customers increase day by day. At this time, it is necessary to consider the financing and share expansion plan in advance to cope with the gradually increasing capital pressure. External investors must pay the subscription funds on time by volume; otherwise, the equity proportion and distribution method shall be assessed in terms of timeliness of funds, precision of time and other aspects. The innovative equity structure in this paper reserves the external financing ability of the company in the later stage and does not affect the control right of the shareholders who initially join the company.

\subsection{Disbandment risk}

Shareholders will focus on personal income when the market, sales volume and profits tend to be stable. However, significant deviation will be caused leading to the division of the company without a scientific and reasonable distribution system in advance. The principle of "Don't race horses" is strictly implemented according to the performance in the two stages of the management team's options to reach the standard and transformation. In the case of members' departure, the company will force the buyback of the untransformed part and leave it to the new operating team. Moreover, the plan of the repo funding must be signed without affecting the operation of the company. The transformed part can be held or transferred as equity, while the founding shareholders, operating team and external shareholders own preferential subscription rights after the external transfer price is finalized, after which the remaining part can be transferred to the new shareholders. In the system, annual tasks and work plans and standards can be clearly defined to make strict assessment and implementation. Before departure, external shareholders must first contact the intended shareholders to negotiate the equity transfer plan and then submit it to the board of directors for discussion. If the plan is feasible, the founding shareholders, operating team and external shareholders own preferential subscription rights, after which the remaining part can be transferred to the new shareholders. The founder can only exit after the cancellation of the company.

\subsection{Brand risk}

Intensified competition, reduced margins and emerging products jointly contribute to the fact that the brand risk of enterprises may break out at any time and lose recognition among customers. Therefore, in the early stage of entrepreneurship, investors with resources should be given priority, which is conducive to building its personal brand for the company. After being recognized by customers in the market, it will form products that are not easy to be replaced and then build brand advantages. Meanwhile, part of the investment can be used for innovative research and development of products to prevent obsolescence.

\subsection{Commitment risk}

The principle of altruism and win-win must be firmly held and the commitments should be strictly fulfilled no matter for internal employees, external customers or suppliers. At the earlier stage of agreement, the sharers participating in the profits are not partners but only the external investors; at the later stage, dividend is limited by setting threshold according to business capability, so as to protect the benefit of shareholders.

\section{Conclusions}

In the era of "mass entrepreneurship and innovation", the number of start-up companies is gradually increasing. At the beginning of entrepreneurship, the design and improvement of equity structure play an important role in the later stage of corporate development. The equity structure proposed in this paper can prevent and control major risks at all stages of the company's development, having the realistic value.

\section{ACKNOWLEDGMENT}

This work was supported by key disciplines of Business Administration of Hubei Polytechnic University and a teaching research project of Hubei Ministry of Education, 
which is "Research on the construction of entrepreneurial education network platform driven by interest and fragmented learning mode" (Project No.2017444); earlier research project of "the $14^{\text {th }}$ five year plan" of the disabled's career planning of CDPF in 2019, "Research on the application of visual sign language translation services for the deaf" (Project No.2019312).

\section{REFERENCES}

1. Wei Min. Types and applicable conditions of equity structure of listed companies [J]. China International Business, 2017(22): 143-144

2. Wang Junwei. Key points of venture equity structure design [J]. Directors\& Boards, 2015 (11): 103-105

3. Dai Peihong. The design of equity structure is required in the start-up period- Based on the historical experience of struggling for capital in Vanke Co., Ltd [J]. Science \& Technology Industry Parks, 2016(11): $83-86$

4. Ni Haojun. Analysis and Discussion on the equity of startup enterprises[J]. Shanxi Agricultural Economy, 2016(08): 79-81

5. Wang Sheng. Research on ownership structure and corporate governance $[\mathrm{J}]$. China Journal Commerce, 2020(08):230-231

6. Li Xiang. Reasonable equity structure design is the cornerstone of successful multi-shareholder companies [J]. Science \& Technology Industry Parks, 2016(09):93-95

7. Yang Heyuan, Zhang Guijie. Analysis on the equity structure of China's listed companies[J]. Economic Trade, 2015(07),37-38

8. Chi Zhaomei, Chen Bingjun. The influence of dual ownership structure on the control rights of founders-Based on MI's listing in Hong Kong[J]. Finance and Accounting Monthly, 2020(09):13-20

9. Liu Congxia, Analysis of the adjustment and supervision of the company's ownership structure[J]. Western Finance and Accounting, 2013(09):36-38 